\title{
Erratum to: $6^{\mathrm{e}}$ Congrès européen de médecine tropicale et santé internationale (Vérone, 6 au 10 septembre 2010)
}

\section{Erratum to: 6th European Congress on Tropical Medicine and International Health} (Verona, 6-10 September 2010)

(C) Société de pathologie exotique et Springer-Verlag France 2011

Erratum to: Bull Soc Pathol Exot DOI 10.1007/s13149-010-0082-8.

Le titre correct de ces comptes rendus de congrès est : $6^{\mathrm{e}}$ Congrès européen de médecine tropicale et santé internationale (Vérone, 6 au 10 septembre 2009) / 6th European Congress on Tropical Medicine and International Health (Verona, 6-10 September 2009). 